\title{
Red blood cell variables and correlations with body mass components in boys aged 10-17 years
}

\author{
Jasmina Pluncevic Gligoroska ${ }^{1 \odot}$, Serjoza Gontarev², Vesela Maleska, \\ Ljudmila Efremova ${ }^{1}$, Daniela Shukova Stojmanova ${ }^{2}$, Sanja Manchevska ${ }^{1}$ \\ ${ }^{1}$ Institute of Physiology and Anthropology, Faculty of Medicine, and ${ }^{2}$ Faculty of Physical Education, Health and Sport, University Ss \\ Cyril and Methodius, Skopje, Republic of Macedonia.
}

\begin{abstract}
The objective of this study was to analyze the hematologic parameters and their correlation with body composition components in healthy boys at pubertal age. One hundred and ninety physically active male subjects, aged 10 to 17 years, mean age $13.87 \pm 4.5$ years, were included in the study. Capillary blood was drawn from all subjects and the following hematologic parameters were measured: RBC, Hct, Hb, MCV, MCH, MCHC. The following body components derived from Matiegka anthropometric method were assessed: muscle mass $(\mathrm{MM})$, bone mass $(\mathrm{BM})$, and body fat mass $(\mathrm{BF})$. The mean values $( \pm \mathrm{SD})$ of hematologic parameters were: $\mathrm{RBC}=$ $4.87 \pm 0.41 \times 10^{12} / \mathrm{L}, \mathrm{Hb}=14.24 \pm 1.24 \mathrm{~g} / \mathrm{dL}, \mathrm{Hct}=43.83 \pm 3.8 \%$. Anthropometric characteristics were as follows: body mass index $(\mathrm{BMI})=20.26 \pm 3.27 \mathrm{~kg} / \mathrm{m}^{2}$, relative muscle mass $(\mathrm{MM} \%)=53.18 \pm 3.19 \%$, bone mass $(\mathrm{BM} \%)=18.83 \pm$ $2.4 \%$ and body fat percentage $(\mathrm{BF} \%)=15.19 \pm 2.64 \%$. Correlation analysis between hematologic parameters and body composition showed a moderate to strong correlation between RBC, $\mathrm{Hb}$ and Hct and all body components. The strongest correlations were found between $\mathrm{Hb}$ and Hct, and muscle mass $(\mathrm{r}=0.60 ; \mathrm{r}=0.61)$ and lean body mass $(r=0.59)$. The body fat mass showed also a positive association with RBC ( $r=0.47) ; \mathrm{Hb}(\mathrm{r}=0.47)$ and Hct $(\mathrm{r}=0.48)$. Our findings showed that the relationship between anthropometric measures and RBC variables in healthy physically active boys were positively correlated, but the level of association was higher with skeletal muscle mass.
\end{abstract}

Key words: red blood cells, hemoglobin, hematologic indices, body composition, boys.

Changes in the physical appearance that happen during the rapid growth periods of life are accompanied with developmental changes in all physiological systems. Normal physical development of young people is reflected in the changes of body components, increase in muscle and bone mass, and decrease in fat component. ${ }^{1-3}$ Blood as the vitally important physiological system also undergoes big changes in the adolescent period, which are manifested with a significant increase in the hematologic markers and attaining levels established in the adult age. ${ }^{4}$

凶Jasmina Pluncevic Gligoroska jasnapg965@yahoo.com

Received 17th May 2018; revised 21st July 2018, 30th August 2018; accepted 9th September 2018
During puberty there is often an imbalance between the increased bodily needs for energetic and building food components and the acquisition of inappropriate food habits, which could lead to different deficiencies, such as iron deficiency anemia.-7 Therefore, the assessment of nutritional status in adolescents is very important for proper assessment of growth of adolescents. The complete nutritional status includes estimation of body composition and various biochemical analyses, especially evaluation of hematologic parameters. ${ }^{8}$ Hematologic parameters such as hemoglobin, hematocrit and red blood cell count (RBC) are useful for the assessment of nutritional status in healthy individuals. ${ }^{9}$ The association between hematologic markers, especially hemoglobin and serum iron level, with body composition 
are investigated in different populations, regarding age, sex and health status. ${ }^{10,11}$ The findings predominantly have shown a positive association between hematologic parameters and skeletal muscle mass and an inverse association with body fat and body mass index. $^{12-14}$

The aim of this study is to investigate the correlation between skeletal muscle mass (SMM) and RBC variables. We hypothesized that the association between RBC variables and lean body mass (LBM) is stronger than the association with fat mass. Therefore, it was our aim to determine the strength of association between body mass components and hematologic parameters in healthy adolescent boys.

\section{Material and Methods}

The study population included 190 male participants, physically active boys, aged between 10 and 17 years, randomly selected from the subjects who participated in regular preparticipation examination (PPE) in the Center of Sports Medicine, Institute of Physiology, Medical Faculty, UKIM, Skopje, Republic of Macedonia between March and July 2016.

\section{Hematologic analysis}

Hematologic testing was part of the complete medical check-up for sport pre-participation screening, during morning hours (from 8:00 to $12: 00 \mathrm{am}$ ) in a controlled laboratory with constant temperature (between $20^{\circ} \mathrm{C}$ and $24^{\circ} \mathrm{C}$ ) and humidity. The blood samples were collected from capillary vessel using sterile plastic containers with anticoagulant (EDTA K3) incorporated in its walls. An experienced evaluator was in charge of the collection procedures. Analysis was done by automated hematology analyzer ABX Micros 60-OT (ABX hematology, Montpelier, France). The following hematologic parameters were analyzed: red blood cell (RBC) count, hematocrit $(\mathrm{Ht})$, hemoglobin concentration $(\mathrm{Hb})$, mean cell volume $(\mathrm{MCV})$, mean cell hemoglobin $(\mathrm{MCH})$ and mean cell hemoglobin concentration (MCHC).

\section{Anthropometric measures}

Body composition was assessed using the anthropometric measurement protocol by Matiegka. Besides the standing height and weight, the following anthropometric parameters were also measured: Five limb circumferences (upper arm relaxed and flexed, forearm, thigh and calf), four limb diameters (wrist, elbow, ankle and knee) and seven skinfolds (biceps, triceps, forearm, subscapular, thigh, calf, suprailiac). All measurements were performed on the right side of the body. Participants' height was measured to the nearest $0.1 \mathrm{~cm}$ with a fixed stadiometer (Holtain Ltd., Crymich, U.K.) and body weight to the nearest $0.1 \mathrm{~kg}$ using the SECA beam balance (Seca, Hamburg, Germany). Harpenden skinfold caliper (British indicators Ltd., Luton) was used to measure skinfold thickness with $0.1 \mathrm{~mm}$ accuracy and the ankle diameter was measured using Vernier caliper. Elastic tape was used to measure circumferences with 0.01 accuracy. An anthropometry expert performed the anthropometric measurements according to the guidelines of the International Society for the Advancement of Kinanthropometry. Personal information of the participants (full name, date of birth, activity record) as well as anthropometric data were filled in on special forms. The final parameters from Matiegka's body composition assessment were muscle mass (MM), bone mass (BM) and fat mass (FM) expressed as absolute values in kilograms and the same parameters expressed as relative values in percentage of the whole body mass: $\mathrm{MM} \%, \mathrm{BM} \%$ and $\mathrm{FM} \%$. Lean body mass was also assessed (LBM).

\section{Ethics}

The study was undertaken in compliance with the Declaration of Helsinki and approved by the Human Research Ethics Committee of the Medical Faculty, UKIM, Skopje (IRB number: 03-5338/5). The children and their parents gave 
written informed consent after having been introduced to the procedures, benefits and possible risks of participation in the study.

\section{Statistical Analysis}

Data were analyzed using the statistical program for Windows, STATISTICA, version 7.1. Data were inspected for normal distribution using the Kolmogorov-Smirnov test. Results are expressed as mean \pm SD (standard deviation), and minimum and maximum values are also presented. Multivariate analysis was used to assess significant differences for anthropological and hematologic parameters between age different groups $(p<0.05)$. The strength of the association between the variables was estimated by Pearson correlation coefficient. Statistical significance was set at $p \leq 0.05$. Multiple regression analysis between $\mathrm{RBC}$ variables as dependent variable and body composition parameters as predictors (constant) was made to assess the influence between analyzed variables.

\section{Results}

Table I outlines anthropometric characteristics and hematologic parameters of the participants. The mean age of the participants in this study was $13.37 \pm 2.77$ years (10-17). All analyzed parameters were in the normal value range for a specific parameter. Anthropometric characteristics were as follows: Body mass index $(\mathrm{BMI})=20.26 \mathrm{~kg} / \mathrm{m}^{2}$, relative muscle mass $(\mathrm{MM} \%)=53.18 \%$, which suggested that the muscle mass was well developed. The mean value of bone mass (BM\%) was 18.83, suggesting that the subjects were in an active growth phase. The body fat percentage $(\mathrm{BF} \%)$ was $15.19 \%$, which is considered as an optimal value for this parameter for physically active boys. $95.8 \%$ of all participants had normal red blood count (RBC) within the interval of normal range for this parameter (3.87 to $6.32 \mathrm{x}$ $10^{12} / \mathrm{L}$ ), with $\mathrm{RBC}$ mean value of $5.02 \times 10^{12} / \mathrm{L}$. Hemoglobin concentration varied from low levels $(11 \mathrm{~g} / \mathrm{dL})$ in only eight subjects $(4.2 \%)$ to very high levels of $17.9 \mathrm{~g} / \mathrm{dL}$ (in one subject),

Table I. Anthropometric characteristics, body composition and hematologic parameters of male adolescents $(\mathrm{N}=190)$.

\begin{tabular}{lcccc}
\hline & Mean & SD & min & max \\
\hline Age $($ year $)$ & 13.87 & 4.5 & 10 & 17 \\
Height $(\mathrm{cm})$ & 163.83 & 15.8 & 129.6 & 186 \\
Weight $(\mathrm{kg})$ & 55.68 & 16.9 & 26 & 100 \\
BMI $\left(\mathrm{kg} / \mathrm{m}^{2}\right)$ & 20.26 & 3.27 & 14.38 & 33.62 \\
LBM (Lean Body Mass) kg & 46.56 & 14.23 & 14.9 & 80.07 \\
MM (Muscular mass) kg & 30.02 & 9.73 & 12.93 & 60.1 \\
MM\% & 53.18 & 3.19 & 40.85 & 61.81 \\
BM (Bone mass) kg & 10.45 & 2.8 & 5.56 & 23.45 \\
BM\% & 18.83 & 2.14 & 12.43 & 26.13 \\
BFM (Body fat mass) kg & 8.64 & 3.64 & 3.55 & 31.22 \\
BF\% & 15.19 & 2.64 & 11.06 & 28.33 \\
RBC $\left(10^{12} / \mathrm{dl}\right)$ & 4.87 & 0.41 & 3.87 & 6.32 \\
Hb $(\mathrm{gr} / \mathrm{dl})$ & 14.24 & 1.24 & 11 & 17.9 \\
$\mathrm{Hct}(\%)$ & 43.83 & 3.8 & 34 & 53.8 \\
$\mathrm{MCV}\left(\mu \mathrm{m}^{3}\right)$ & 86.47 & 3.74 & 72 & 94 \\
$\mathrm{MCH}(\mathrm{pg})$ & 28.15 & 1.7 & 19.9 & 31.8 \\
$\mathrm{MCHC}(\mathrm{g} / \mathrm{dl})$ & 32.54 & 1.25 & 27.7 & 35.8 \\
\hline
\end{tabular}

MM: muscular mass; BM: bone mass; FM: Fat mass; LBM: lean body mass; BMI: body mass index; RBC: red blood cells; $\mathrm{Hb}$ : hemoglobin, Hct: Hematocrit; MCV: Mean corpuscular volume; MCH: mean corpuscular hemoglobin, MCHC: mean concentration of hemoglobin 
within narrow confidence interval of $14.08 \mathrm{~g} /$ $\mathrm{dL}$ to $14.63 \mathrm{~g} / \mathrm{dL}$, with mean level of $14.24 \mathrm{~g} / \mathrm{L}$. The mean values of hematologic indices, $\mathrm{MCV}$ (which measures mean cell volume), $\mathrm{MCH}$ (which shows the amount of hemoglobin in one average erythrocyte) and MCHC (which shows mean cell $\mathrm{Hb}$ concentration), were in the range of normal reference values.

Table II summarizes anthropometric and hematologic parameters for three age different subgroups: group U12: boys aged 10 to 12 years, group U14: 12 to 14 years, and U17: 14 to 17 years old. Since the age span included a broad period of growth and development (10-17 years), due to the lack of physical examination of puberty stage (Tanner's staging) we divided the participants into three groups which covered the different stages of growth. The majority of anthropometric and hematologic parameters were statistically different between the different age groups, with a tendency to rise with increasing age. Only bone mass percentage was higher in younger groups. The body fat percentage (BF \%) was insignificantly different in all three groups.

The values of the Pearson correlation coefficient (r) between RBC variables and body mass components which are expressed in kilograms (MM - muscle mass; BM - bone mass; FM - fat mass) and relative body mass components, expressed as percentage of whole body weight (MM\%; BM\%; FM\%) are displayed in Table III. Correlation analysis between hematologic parameters and body composition components showed moderate to good correlations between red blood cell counts, hemoglobin levels and hematocrit levels with all body components. The strongest correlations were found between hemoglobin and hematocrit levels and muscle mass $(r=0.60 ; r=0.61)$ and lean body mass $(r=$ $0.59)$. Negative correlations were found between all hematologic parameters and relative bone mass (BM\%).

Table IV shows the results of the multivariate regression analysis between RBC variables as

Table II. Anthropometric characteristics, body composition and hematologic parameters of male adolescents divided into different age groups $(\mathrm{N}=190)$.

\begin{tabular}{|c|c|c|c|}
\hline & U12 (N=70) & $\mathrm{U} 14(\mathrm{~N}=70)$ & U17 (N=50) \\
\hline Weight (kg) & $40.91(9.89)^{\mathrm{bc}}$ & $57.35(15.85)^{\mathrm{ac}}$ & $66.41(12.21)^{\mathrm{ab}}$ \\
\hline Height $(\mathrm{cm})$ & $148.29(8.59)^{b c}$ & $165.08(10.48)^{\mathrm{ac}}$ & $177.21(7.83)^{\mathrm{ab}}$ \\
\hline $\mathrm{MM}(\mathrm{kg})$ & $20.87(5.13)^{\mathrm{bc}}$ & $28.72(7.62)^{\mathrm{ac}}$ & $35.97(8.22)^{\mathrm{ab}}$ \\
\hline MM (\%) & $51.21(2.72)^{\mathrm{bc}}$ & $52.77(2.77)^{\mathrm{ac}}$ & $53.76(3.37)^{\mathrm{a}}$ \\
\hline $\mathrm{BM}(\mathrm{kg})$ & $7.91(1.5)^{\mathrm{bc}}$ & $9.51(2.75)^{\mathrm{a}}$ & $9.45(1.25)^{\mathrm{a}}$ \\
\hline BM (\%) & $19.82\left(1.71^{\mathrm{c}}\right.$ & $19.08(2.28)^{c}$ & $18.21(4.11)^{\mathrm{ab}}$ \\
\hline $\mathrm{BF}(\mathrm{kg})$ & $6.59(2.73)^{b c}$ & $9.10(4.05)^{\mathrm{ac}}$ & $9.75(2.87)^{\mathrm{a}}$ \\
\hline $\mathrm{BF}(\%)$ & $16.02(3.02)^{\&}$ & $16.10(3.71)^{\&}$ & $15.94(6.21)^{\&}$ \\
\hline LBM (kg) & $33.24(6.82)^{\mathrm{bc}}$ & $44.96(9.80)^{\mathrm{ac}}$ & $54.89(9.52)^{\mathrm{ab}}$ \\
\hline BMI $\left(\mathrm{kg} / \mathrm{m}^{2}\right)$ & $18.75(3.01)^{\mathrm{bc}}$ & $20.39(3.57)^{\mathrm{ac}}$ & $21.65(3.42)^{\mathrm{ab}}$ \\
\hline $\mathrm{RBC}\left(10^{12} / \mathrm{dl}\right)$ & $4.83(0.33)^{\mathrm{bc}}$ & $5.08(0.40)^{\mathrm{ac}}$ & $5.21(0.51)^{\mathrm{a}}$ \\
\hline $\mathrm{Hb}(\mathrm{gr} / \mathrm{dl})$ & $13.31(0.96)^{\mathrm{bc}}$ & $14.32(1.15)^{\mathrm{ac}}$ & $14.92(1.19)^{\mathrm{ab}}$ \\
\hline Hct (\%) & $40.84(4.89)^{\mathrm{bc}}$ & $44.20(3.37)^{\mathrm{ac}}$ & $45.91(3.52)^{\mathrm{ab}}$ \\
\hline $\operatorname{MCV}\left(\mu \mathrm{m}^{3}\right)$ & $84.24(3.54)^{\mathrm{bc}}$ & $86.88(4.49)^{a}$ & $87.97(4.80)^{\mathrm{ab}}$ \\
\hline $\mathrm{MCH}(\mathrm{pg})$ & $27.09(1.82)^{\&}$ & $27.34(2.06)^{\&}$ & $28.38(2.36)^{\&}$ \\
\hline $\mathrm{MCHC}(\mathrm{g} / \mathrm{dl})$ & $32.51(1.25)^{\&}$ & $31.42(2.90)^{\&}$ & $31.98(1.56)^{\&}$ \\
\hline
\end{tabular}

U12: 10 to 12 years; U14: 12-14 years; U17: 14- 17 years old

* significant differences between different age groups was significant at level $\mathrm{p}<0.005$

\& no significant difference with other groups; ${ }^{\text {a }}$ significantly different from U12; ${ }^{b}$ significantly different from U14;

c significantly different from U17 
Table III. Correlations between hematological parameters and body components.

\begin{tabular}{lcccccccc}
\hline & MMkg & MM\% & BMkg & BM\% & FMkg & FM \% & LBM & BMI \\
\hline RBC $\left(10^{12} / \mathrm{dl}\right)$ & $0.474^{*}$ & 0.114 & $0.416^{*}$ & $-0.321^{*}$ & $0.424^{*}$ & 0.109 & $0.439^{*}$ & $0.374^{*}$ \\
$\mathrm{Hb}(\mathrm{gr} / \mathrm{dl})$ & $0.603^{*}$ & $0.254^{*}$ & $0.577^{*}$ & $-0.301^{*}$ & $0.477^{*}$ & 0.019 & $0.586^{*}$ & $0.352^{*}$ \\
$\mathrm{Hct}(\%)$ & $0.615^{*}$ & $0.177^{*}$ & $0.574^{*}$ & $-0.329^{*}$ & $0.487^{*}$ & 0.024 & $0.590^{*}$ & $0.397^{*}$ \\
$\mathrm{MCV}\left(\mu \mathrm{m}^{3}\right)$ & $0.380^{*}$ & $0.163^{*}$ & $0.401^{*}$ & -0.101 & $0.212^{*}$ & $-0.156^{*}$ & $0.399^{*}$ & 0.124 \\
$\mathrm{MCH}(\mathrm{pg})$ & $0.246^{*}$ & $0.212^{*}$ & $0.283^{*}$ & -0.006 & 0.133 & -0.110 & $0.268^{*}$ & 0.014 \\
$\mathrm{MCHC}(\mathrm{g} / \mathrm{dl})$ & -0.021 & $0.171^{*}$ & 0.006 & 0.066 & -0.018 & -0.003 & -0.005 & -0.109 \\
\hline
\end{tabular}

* Pearson correlation coefficient was significant at the 0.05 level

MM: muscular mass; BM: bone mass; FM: Fat mass; LBM: lean body mass; BMI: body mass index; RBC: red blood cells; $\mathrm{Hb}$ : hemoglobin, Hct: Hematocrit; MCV: Mean corpuscular volume; MCH: Mean corpuscular hemoglobin, MCHC: Mean concentration of hemoglobin.

Table IV. Multiple regression analysis between RBC variables as dependent variable and body composition parameters as predictors (constant).

\begin{tabular}{lcccc}
\hline Dependent variable & Sum of Squares & Mean Square & $\mathrm{F}$ & $\mathrm{p}$ \\
\cline { 2 - 5 } $\mathrm{RBC}\left(10^{12} / \mathrm{dl}\right)$ & 7.246 & 1.208 & 8.895 & 0.0001 \\
$\mathrm{Hb}(\mathrm{gr} / \mathrm{dl})$ & 99.950 & 16.658 & 15.896 & 0.0001 \\
$\mathrm{Hct}(\%)$ & 1008.765 & 168.127 & 17.929 & 0.0001 \\
$\mathrm{MCV}\left(\mu \mathrm{m}^{3}\right)$ & 505.571 & 84.262 & 7.456 & 0.0001 \\
$\mathrm{MCH}(\mathrm{pg})$ & 54.841 & 9.140 & 3.293 & 0.004 \\
$\mathrm{MCHC}(\mathrm{g} / \mathrm{dl})$ & 8.602 & 1.434 & 0.882 & 0.509 \\
\hline
\end{tabular}

RBC: red blood cells; Hb: hemoglobin; Hct: Hematocrit; MCV: Mean corpuscular volume; MCH: mean corpuscular hemoglobin; MCHC: mean concentration of hemoglobin.

a dependent variable and body composition parameters as predictors (constant). At multivariable level there was a statistically significant influence on analyzed variables. Only one hematologic variable, MCHC, showed a non-significant association with body composition parameters, as it was the case in the correlation analysis as well. Regression analysis at univariate level showed an inverse relationship between $\mathrm{Hb}$, Hct, MCV and BMI.

\section{Discussion}

To the best of our knowledge this is the first study that investigated the relationship between body composition and hematologic parameters in healthy Macedonian boys. Our goal was to determine the strength of the association between body components and red blood cell variables in this population group. The main finding of our study is that higher lean body mass and skeletal muscle mass are associated with higher levels of hemoglobin, red blood cell counts, hematocrit and hematologic indices.

Participants in this study were healthy young children/adolescents who were actively involved in physical activities, that is, they participated in different sports on a regular basis. The body composition analysis showed average values of body components indicating a good level of growth and body development in our young participants. The eventual influence of physical activity on body components and hematologic status was not taken into consideration in this study.

Regarding the correlations between red blood cell variables and body components, we found positive associations between all items of both groups of parameters. Total erythrocytes count or RBC showed a moderate positive correlation with all three body mass components (expressed in kilograms): muscle mass (MM) $\mathrm{r}=0.47$, bone mass $(\mathrm{BM}) \mathrm{r}=0.41$ and body fat mass $(\mathrm{BF})$ 
$\mathrm{r}=0.42$. Hemoglobin concentration and Hct showed almost the same level of association with hematologic parameters: Strong positive correlation with $\mathrm{MM}(\mathrm{r}=0.60)$, lean body mass (LBM, r=0.59), bone mass ( $\mathrm{r}=0.57)$ and moderate positive correlation with $\mathrm{BF}(\mathrm{r}=0.48)$ and $\mathrm{BMI}$ $(\mathrm{r}=0.35)$. Hematologic indices showed weaker associations with body components. MCV and $\mathrm{MCH}$, showed stronger associations with active body components, LBM, MM and BM than with BF. However, we should bear in mind that the participants were healthy physically active adolescents, who predominantly had optimal body composition, which might explain why all body components, including the fat one, have shown a positive correlation with hematologic parameters.

In the literature, the largest number of studies related to the association between hematologic parameters and anthropometric indices have been conducted in adults and overweight or obese children. However, very few studies have examined individuals with normal body weight, and even more scant are data presenting results about children populations between the ages of 10 and 17 years regarding this issue. The majority of data about the association between body composition and hematologic parameters refer to the correlation between body fat mass and serum iron level.

Rates of iron deficiency are higher in overweight children and adults compared to their normal weight counterparts. ${ }^{13-16}$ Although the reason for this is not completely clear, the theory that increased circulating hepcidin-induced iron intakein gastrointestinal system is a scientifically appropriate explanatory mechanism. ${ }^{17}$ It has been noticed that obese children and adolescents may be prone to anemia despite their excessive dietary and caloric intake. ${ }^{18,19}$ The prevalence of anemia in underweight and overweight children is higher than in subjects with desirable weight. ${ }^{20}$ The rate of iron deficiency (ID) among obese and overweight children is twice the rate of children with normal weight. Almost one of every ten overweight adolescent has ID. ${ }^{13}$ In his study (thesis) Ahlgrim ${ }^{21}$ found that high fat mass was associated with small blood volume per $\mathrm{kg}$. The amount of adipose tissue, which is almost avascular, strongly influences the standardization of values of blood volume per kilogram body mass weight. ${ }^{22}$ Some authors suggest that FFM (fat free mass) could be used as an anthropometric reference for the blood parameters because of the high correlation coefficient between them. ${ }^{23}$

Studies have reported that obesity has an adverse effect on iron metabolism, which is registered with low serum iron and low hemoglobin levels. ${ }^{25} \mathrm{~A}$ large study confirmed that overweight children were twice as likely to be iron deficient comparing to normal weight children. ${ }^{13}$ In their study conducted among school children in Iran, Moayeri et al. ${ }^{19}$ found that the prevalence of iron deficiency increased with subject's body mass index. A similar study was performed in the adult population in Iran, but the correlation between BMI and hemoglobin, $\mathrm{MCV}$, serum iron and other hematologic indices was not found..$^{24}$ In the Third National Health and Nutrition Examination Survey (NHANES III) the association between serum ferritin and adiposity was analyzed. The study reported a moderately positive correlation between serum ferritin and obesity indices: WHR ( $\mathrm{r}=0.36)$; $\mathrm{BMI}$ $(\mathrm{r}=0.34)$; waist circumferences $(\mathrm{r}=0.34)$ and sum of skinfolds $(\mathrm{r}=0.32) .{ }^{25}$ There has been substantial evidence suggestive of an association between iron status and body fat mass. However, a few studies failed to determine the association between iron deficiency and BMI and body fat. The contradictory findings of this study may be due to the good health and nutritional status of the investigated group (young women, military recruits). ${ }^{26}$ The results obtained in our study showed a positive relationship between majority of RBC variables and body fat mass, but lower intensity regarding the relationship with active body components, LBM, muscle and bone components.

In the published literature there are few data on the relationship between lean body mass i.e. muscle mass and hematologic markers. Our results are in agreement with the existing 
ones in similar studies. The level of association between RBC variables and BMI, LBM and muscle mass were similar to the other reported findings. In a study of the relationship between body composition and complete blood count in Korean university students, a moderate positive correlation was found between $\mathrm{RBC}, \mathrm{Hb}$, Hct and hematologic indices and weight, height, BMI, skeletal muscle mass and basal metabolic rate. The strongest correlation coefficient was found between SMM and $\mathrm{Hb}$ ( $\mathrm{r}=0.663)$, Hct and weight $(\mathrm{r}=0.536)$. Body fat percentage $(\mathrm{BF} \%)$ showed weak to moderate negative correlation with $\mathrm{RBC}, \mathrm{Hb}$, Hct and indicies (-0.39; -0.434 ; $-0.432 ;-0.169$, respectively). ${ }^{27}$ A correlation analysis between body composition and blood parameters carried on a group of one hundred students revealed a high correlation coefficient between hemoglobin and body weight $(\mathrm{r}=0.65)$ and lean body mass $(\mathrm{r}=0.69) .{ }^{28}$ Higher levels of hemoglobin were associated with higher muscle density, higher muscle area and lower fat area. ${ }^{22}$ In a study that analyzed the association between anthropometric parameters and biochemical profile, positive associations between RBC, $\mathrm{Hb}$ and Hct and BMI were observed $(\mathrm{r}=0.53$, 0.65 , 0.61; all $\mathrm{p}<0.001) .{ }^{24}$ Hemoglobin levels are associated with muscle body component (obtained by peripheral quantitative computed tomography, pQCT), and occur in the presence of anemia in elderly people. ${ }^{25}$

The findings of other studies predominantly showed a positive association between hematologic parameters and skeletal muscle mass and an inverse association with body fat and body mass index. Our results demonstrated that young healthy physically active boys with proper body weight and composition showed positive correlations between hematologic parameters and all body components (muscle mass, bone mass and body fat), but the strongest correlation was found between hemoglobin level and hematocrit with skeletal muscle mass and lean body mass. The knowledge and understanding of the relationship between RBC variables and body composition parameters could be important in healthcare planning for children and youth.

\section{REFERENCES}

1. Loomba-Albrecht LA, Styne DM. Effect of puberty on body composition. Curr Opin Endocrinol Diabetes Obes 2009; 16: 10-15.

2. Siervogel RM, Demerath EW, Schubert C, et al. Puberty and body composition. Horm Res 2003; 60(Suppl 1): 36-45.

3. Boyne MS, Thame M, Osmond C, et al. Growth, body composition, and the onset of puberty: longitudinal observations in afro-caribbean children. J Clin Endocrinol Metab 2010; 95: 3194-3200.

4. Jacob EA. Hematological differences in newborn and aging: a review study. Hematol Transfus Int J 2016; 3: 178-190.

5. Nutrition in adolescence - Issues and Challenges for the Health Sector. Issues in Adolescent Health and Development. WHO Library Cataloguing-in-Publication Data 2005. Retrieved on July 21 2017from http://apps.who.int/iris/ bitstream/10665/43342/1/9241593660_eng.pdf

6. Newbold K, Jacobson MS. Adolescent Nutrition: Assessment and Management. New York: Chapman \& Hall, 1996: 677-679.

7. DiMeglio G. Nutrition in adolescence. Pediatr Rev 2000; 21: 32-33.

8. Stang J, Story M. Nutrition Screening, Assessment and Intervention. Guidelines for Adolescent Nutrition Services. 2005: 35-54. htpp://www.epi. umn.edu/let/pubs/adol_book.shtm (Retrieved on June 28 2017)

9. Khan Z, Nawaz M, Khan A, Bacha U. Hemoglobin, red blood cell count, hematocrit and derived parameters for diagnosing anemia in elderly males. Proc Pakistan Acad Sci 2013; 50: 217-226.

10. Gore CJ, Hopkins WG, Burge CM. Errors of measurement for blood volume parameters: a metaanalysis. J Appl Physiol 2005; 99: 1745-1758.

11. Sawka MN, Young AJ, Pandolf KB, Dennis RC, Valerie CR. Erythrocyte, plasma, and blood volume of healthy young men. Med Sci Sport Exerc 1992; 24: 447-453.

12. Pinhas-Hamiel O, Newfield RS, Koren I, Agmon A, Lilos P, Phillip M. Greater prevalence of iron deficiency in overweight children and adolescents: a risk group for iron deficiency. Int J Obes Relat Metab Disord 2003; 27: 416-418.

13. Nead KG, Halterman JS, Kaczorowsky JM, Auinger $P$, Weitzman M. Overweight children and adolescents: a risk group for iron deficiency. Pediatrics 2004; 114: 104-108. 
14. Yanoff LB, Menzie CM, Denkinger B, et al. Inflammation and iron deficiency in the hypoferremia of obesity. Int J Obes (Lond) 2007; 31: 1412-1419.

15. Micozzi MS, Albanes D, Stevens RG. Relation of body size and composition to clinical biochemical and hematological indices in US men and woman. Am J Clin Nutr 1989; 50: 1276-1281.

16. Brotanek JM, Gosz J, Weitzman M, Flores G. Iron deficiency in early childhood in the United States: risk factors and racial/ethnic disparities. Pediatrics 2007; 120: 568-575.

17. Bekri S, Gual P, Anti R, et al. Increased adipose tissue expression of hepcidin in severe obesity is independent from diabetes and NASH. Gastroenterology 2006; 131: 788-796.

18. Saloojee H, Pettifor JM. Iron deficiency and impaired child development. BMJ 2001; 323: 1377-1378.

19. Moayeri H, Bidad K, Zadhoush S, Gholami N, Anari S. Increasing prevalence of iron deficiency in overweight and obese children and adolescents (Tehran Adolescent Obesity Study). Eur J Pediatr 2006; 165: 813-814.

20. Keikhaei B, Askari R, Aminzadeh M. Adolescent with unfeasible body mass index: a risk factor for iron deficiency anemia. J Health Med Informat 2012; 3: doi: 10.4172/2157-7420.1000109

21. Ahlgrim C. Beziehung zwischen blutkompartimenten, kardialen dimensionen und ausdauerleistungsfahigkeit. Dissertatione AlbertLudwigs-Universitat-Freiburg, 2010.
22. Chen Z, Smit M, Du H, et al. Blood pressure in relation to general and central adiposity among 500 000 adult Chines men and women. Int J Epidemiol 2015; 44: 1305-1319.

23. Barazzoni R, Cappellari GG, Semolic A, et al. The association between hematological parameters and insulin resistance is modified by body mass indexresults from the North-East Italy MoMa population study. PLoS One 2014; 9: e101590.

24. Ghadiri-Anari A, Nazemian N, VahedianArdakani HA. Association of body mass index with hemoglobin concentration and iron parameters in Iranian population. ISRN Hematology 2014, Article ID 525312, 3 pages. http://dx.doi. org/10.1155/2014/525312 (Retrieved on May 15 2017).

25. Cesari M, Penninx B, Lauretani F, et al. Hemoglobin levels and skeletal muscle: results from the InCHIANTI study. J Gerontol A Biol Sci Med Sci 2004; 59: 249-254.

26. Karl JP, Lieberman HR, Cable SJ, et al. Poor iron status is not associated with overweight or overfat in non-obese pre-menopausal women. J Am Coll Nutr 2009; 28: 37-42.

27. Jo YK, Yoon J, Chou YK, Sung HH. A study on the relationship between body composition analysis and CBC in University Students. Korean J Clin Lab Sci 2016; 48: 269-274.

28. Falz R, Schulze A, FikenzerS, Busse M. Hematological parameters in moderately trained subjects. CSMI 2010; 4: 1-7. 